4 Research Square

\section{Heart ink injection}

\section{Gargioli Cesare ( $\nabla$ cegargioli@yahoo.it)}

S. Raffaele Biomedical Park Foundation
Preprints are preliminary reports that have not undergone peer review.

They should not be considered conclusive, used to inform clinical practice, or referenced by the media as validated information.

\title{
Method Article
}

Keywords: heart, ink injection, blood vessel

Posted Date: July 30th, 2008

DOI: https://doi.org/10.1038/nprot.2008.161

License: (c) (1) This work is licensed under a Creative Commons Attribution 4.0 International License. Read Full License 


\section{Abstract}

\section{Introduction}

With this technique it is possible to label the blood vessel _in vivo_ in order to analyze in whole mount the quantity and quality of blood vessel.

\section{Reagents}

$1.0 \mathrm{ml}$ syringe China Black Ink Stadard anesthetic $\backslash($ Ketamine and Xylazine)

\section{Procedure}

1. Anesthetize the mouse 2 . Using a $1 \mathrm{ml}$ syringe withdraw $0,5 \mathrm{ml}$ of mouse blood from the heart ventricle 3. Inject $1 \mathrm{ml}$ of China Ink and wait for $30 \mathrm{sec} \backslash$ (until the eyes, mouth and legs became black) 4. Quickly dissect and fix in $4 \%$ PFA over night at $4^{\circ} \mathrm{C} 5$. Treat the sample with a solution of $0,5 \% \mathrm{KOH}$ for one day 6 . Treat the sample with a solution of $0,5 \% \mathrm{KOH} / \mathrm{Glycarol} 2: 1$ one day 7 . Treat the sample with a solution of $0,5 \% \mathrm{KOH} /$ Glycerol 1:1 for one day 8 . Treat the sample with $100 \%$ Glycerol for one day $\backslash$ (in order to visualize clearly all the inner blood vessels)

\section{Timing}

4 days

\section{Critical Steps}

Injection in the heart after blood withdrawal

\section{Anticipated Results}

eyes, mouth and legs black stained

\section{Figures}




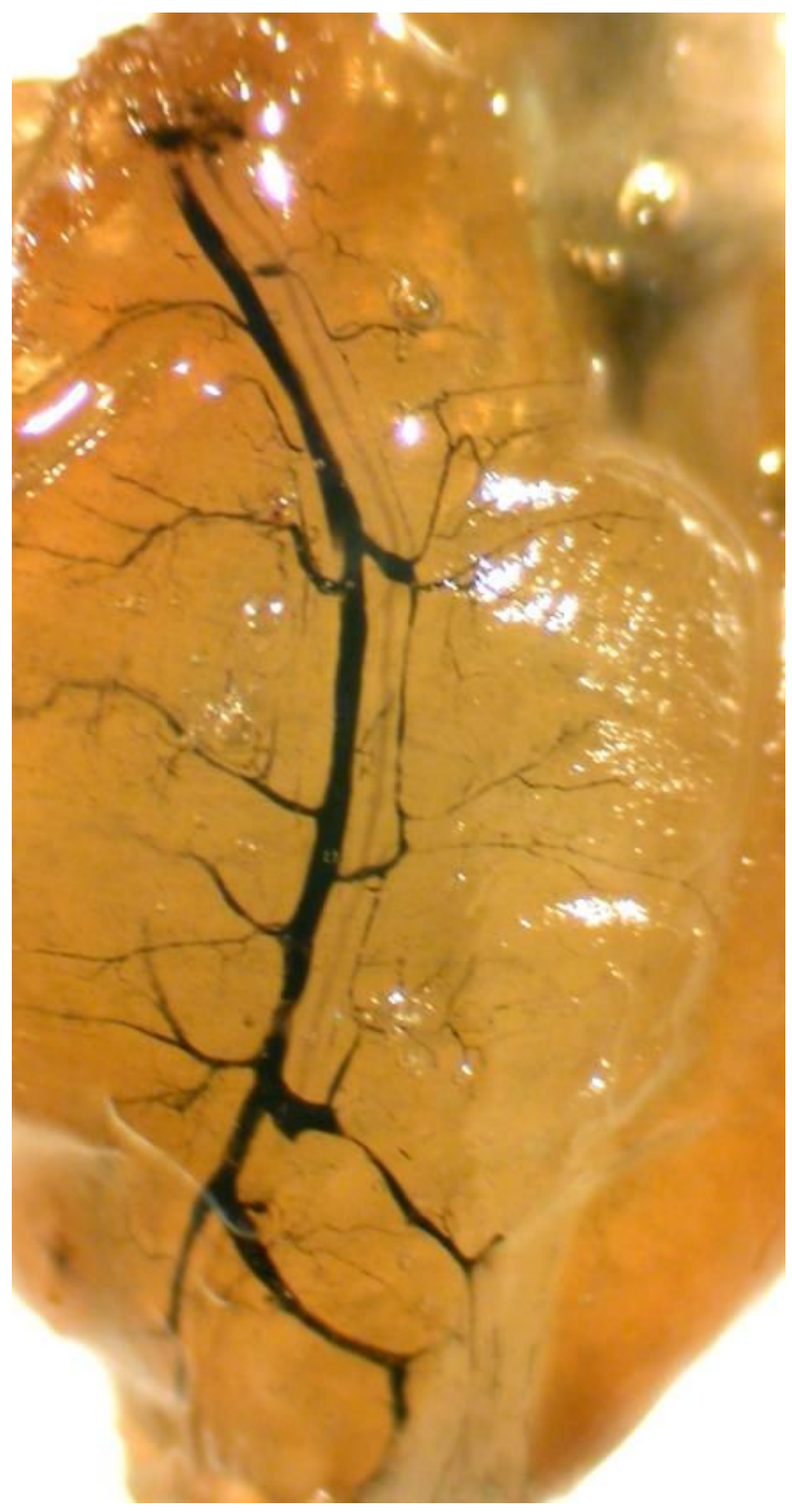

Figure 1 